\title{
Sleep and school education
}

\author{
Sidarta Ribeiro ${ }^{\mathrm{a}, *}$, Robert Stickgold ${ }^{\mathrm{b}}$ \\ anstituto do Cérebro, Universidade Federal do Rio Grande do Norte (UFRN), Natal, Brazil \\ ${ }^{\mathrm{b}}$ Center for Sleep and Cognition, Harvard Medical School, Beth Israel Deaconess Medical Center, Boston, USA
}

\section{A R T I C L E I N F O}

Keywords:

Learning and memory

Sleep

Dream

Pedagogy

\begin{abstract}
A B S T R A C T
Sleep has emerged in the past decades as a key process for memory consolidation and restructuring. Given the universality of sleep across cultures, the need to reduce educational inequality, the low implementation cost of a sleep-based pedagogy, and its global scalability, it is surprising that the potential of improved sleep as a means of enhancing school education has remained largely unexploited. Students of various socio-economic status often suffer from sleep deficits. In principle, the optimization of sleep schedules both before and after classes should produce large positive benefits for learning. Here we review the biological and psychological phenomena underlying the cognitive role of sleep, present the few published studies on sleep and learning that have been performed in schools, and discuss potential applications of sleep to the school setting. Translational research on sleep and learning has never seemed more appropriate.
\end{abstract}

(c) 2014 Published by Elsevier GmbH.

\section{Introduction}

Education in the developed world has recently undergone several changes related to advances in computer technology, psychology, neuroscience, sports and nutritional sciences. Just like medical treatment is becoming a personalized endeavor guided by individual traits, education of the richest has never been so specific, resourceful and hopeful. At the same time, the human population in underdeveloped regions continues to increase, making yet more difficult efforts to produce comparable improvements in the educational capacities of these societies. Even in so-called developed societies, poverty and reduced educational opportunities constitute a long-term risk factor for child outcomes [62]. The growing educational inequality across the globe [65] is a serious problem for future generations. In this context, science-based strategies to boost learning are most welcome, yet must be scalable to large populations, lest them be irrelevant.

Due to their critical importance for learning, the improvement of basic physiological needs such as sleep, nutrition and exercise have obvious potential for a scalable change in education. Sleep is particularly promising as a highly efficacious pedagogical variable, due to its wide applicability. Also, measures to mobilize sleep for education often can be implemented at relatively low cost. Children living in overcrowded environments, youth exposed to unrelenting television and internet stimulation, and adults working night shift jobs all suffer from sleep deficits. Teachers typically

\footnotetext{
*Corresponding author. E-mail address: sidartaribeiro@neuro.ufrn.br (S. Ribeiro).
}

consider sleep among students something to be resisted and opposed, taking it as a clear sign of disengagement from the learning process. Yet, a wealth of converging evidence in humans as well as in animal models shows that sleep deprivation impairs learning (Fig. 1A), and that a wide range of learning benefits can come from optimizing both pre-training and post-training sleep $[15,35,79,90,93,98]$.

\section{Sleep and learning}

Sleep consists of the cyclic occurrence of rapid-eye-movement (REM) and non-REM (NREM) sleep periods. A typical nocturnal sleep period includes 4-5 NREM-REM sleep cycles of approximately 90 min duration. The first NREM-REM sleep cycles are dominated by slow wave sleep (which represents the deepest form of NREM sleep), whereas during late sleep, REM sleep periods become more intense and extended. The need for sleep varies with age, with younger children sleeping $10-12 \mathrm{~h}$ per night whereas $9 \mathrm{~h}$ might be sufficient around puberty. Sleep plays a beneficial role on both the encoding and the consolidation of memories, i.e. the two main stages of memory formation. As a consequence, the success of learning depends on both sufficient amounts of sleep and an optimal sleep "architecture". The acute and chronic restriction of sleep can seriously impair cognitive and emotional functions. Regarding sleep architecture, both REM and NREM sleep have been shown to play critical roles in learning and memory, with NREM sleep, especially its deepest stage of slow wave sleep, being key for the consolidation of episodic memories, 
A

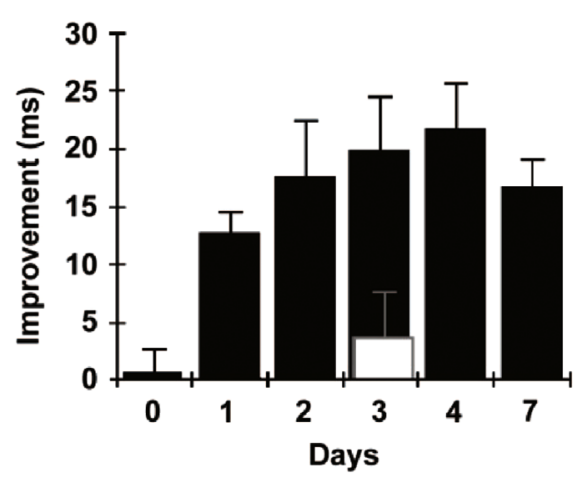

B

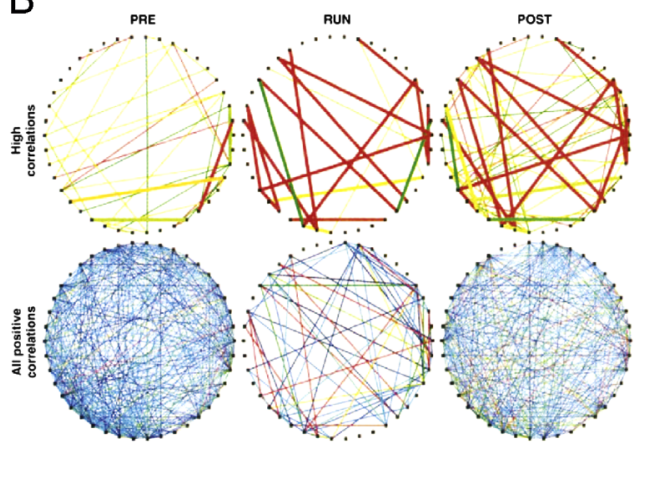

C
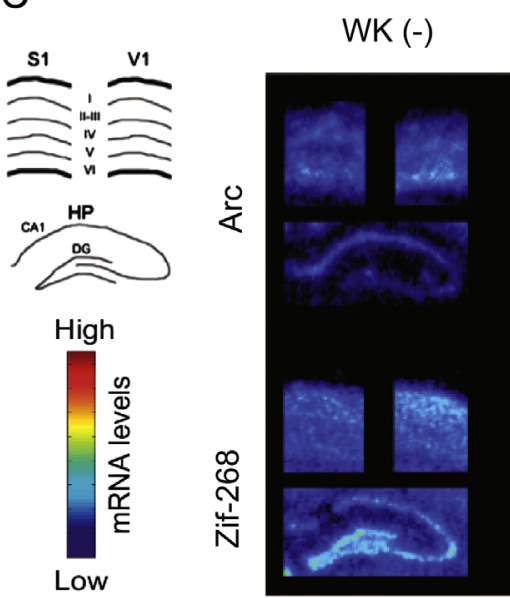

WK $(+)$

SWS (+)

$\operatorname{REM}(+)$
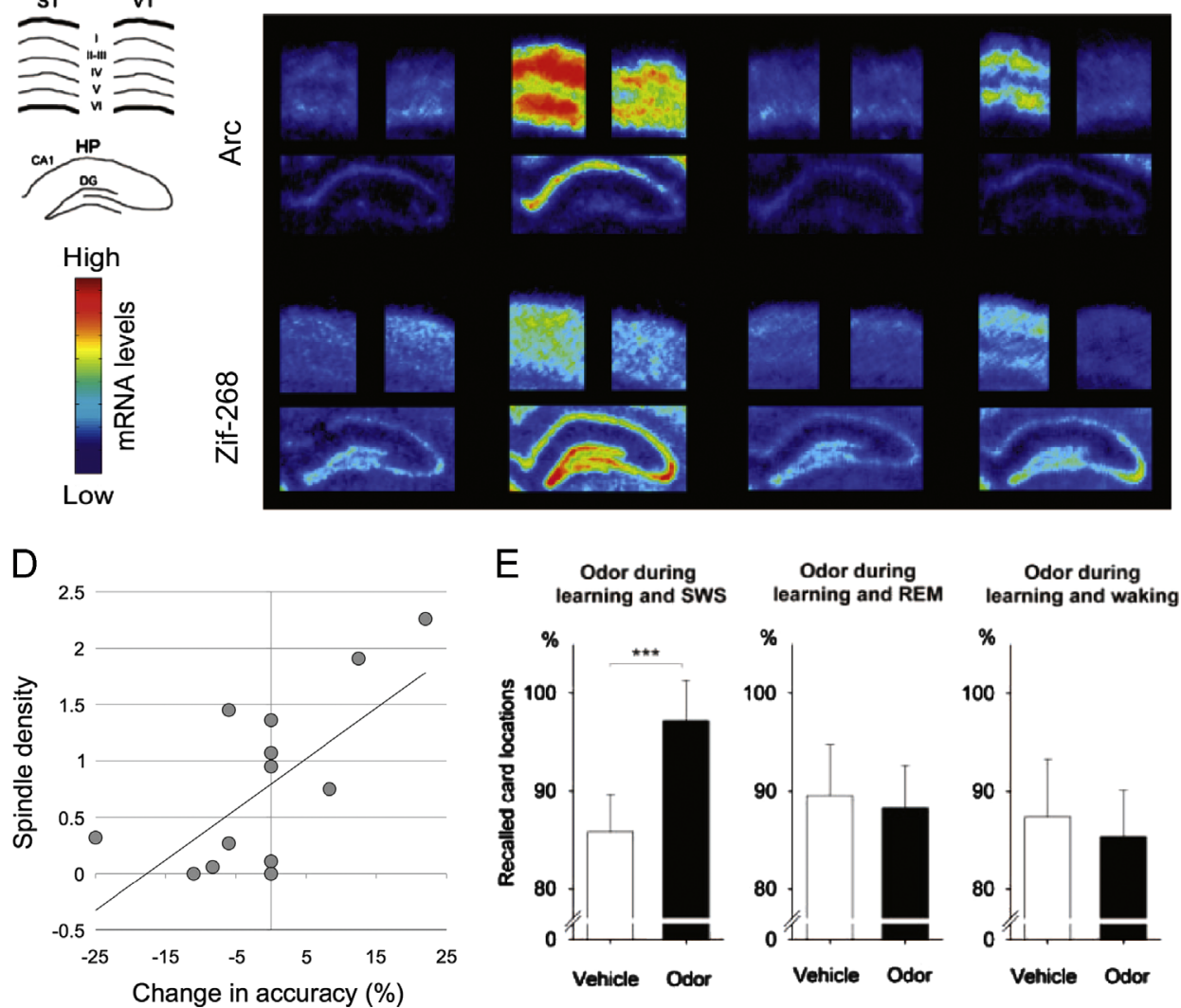

$E$
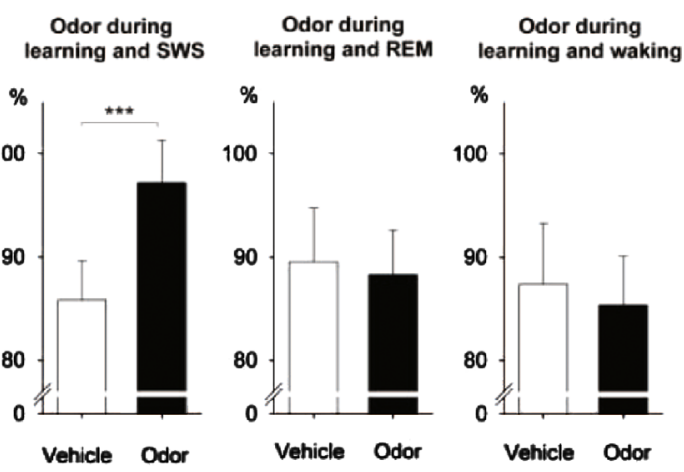

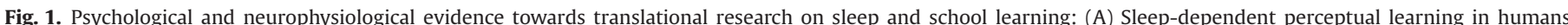

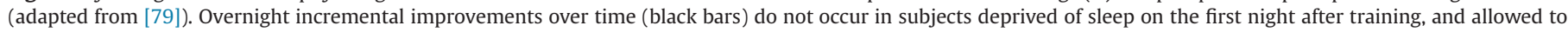

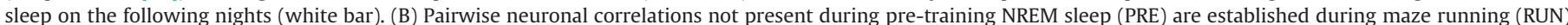

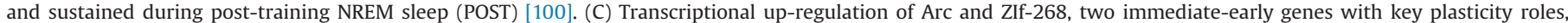

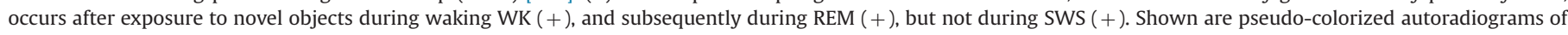

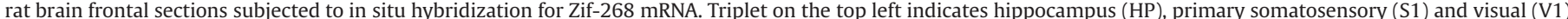

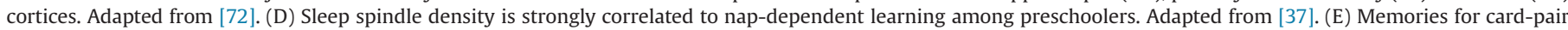

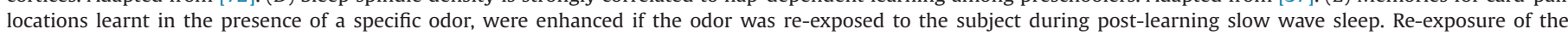

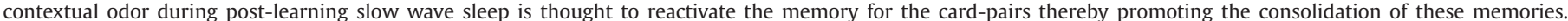
Re-exposure of the odor during REM sleep or waking was ineffective. Adapted from [64].

which are memories for events and their embedding in a spatiotemporal context.

The conscious encoding and retrieval of such memories involves brain structures spanning the prefrontal cortex, medial temporal lobe, and hippocampus. The consolidation of episodic memories is based on the repeated reactivation of the neuronal representations underlying these memories during slow wave sleep. This consolidation not only strengthens such memories but, more importantly, leads to a qualitative reorganization of their representation $[33,63]$. This neuronal reorganization is thought to underlie processes of knowledge abstraction and insight that occur preferentially during post-encoding sleep, but whether it occurs during NREM [80,90] or REM [78] sleep remains unclear [80]. Thus, sleep facilitates both synaptic-level and systems-level consolidation, supporting on the one hand the reorganization and translocation of memories to distill and construct optimal representations of 
learned material $[13,76]$, and on the other to simply stabilize and strengthen the memories in the form in which they were encoded $[11,60,103]$.

The psychological characterization of sleep-dependent learning was accompanied by brain imaging experiments that demonstrated the occurrence of experience-dependent reactivation [44] and neuroanatomical reorganization of mnemonic traces during sleep, in correlation with performance gains over time [21,54]. The search for the electrophysiological substrates of sleep-dependent learning showed that recent learning specifically enhances electroencephalographic (EEG) oscillations that characterize NREM sleep [31,105]. The electrical or auditory augmentation of slow waves during sleep has been shown to improve consolidation of declarative memories $[45,50]$. These findings establish a causal relationship between memory consolidation and these slow oscillations, which favor processes of neuronal synchronization and synaptic potentiation during the up-states of these oscillations $[6,9]$. Higher frequency oscillations, such as the sharp wave-ripple complexes that accompany memory reactivations in the hippocampus, and sleep spindles that co-occur with sharp-wave ripples during the slow oscillation up-state in thalamocortical networks, have also been implicated with learning and memory formation during sleep $[23,34,48,53,74,81]$.

Mnemonic reactivation at the level of single neurons or neuronal assemblies (Fig. 1B) has been demonstrated in animal models mainly during NREM, showing that multi-neuron activity patterns acquired during waking, recur during subsequent sleep [3,4,14,57,59,67,72,100]. However, though difficult to identify, neuronal reactivation might occur also in REM sleep $[42,57,67,72]$. Importantly, the levels of calcium-dependent plasticity factors are up-regulated during REM sleep in an experience-dependent manner [68,69,72,83], and are correlated with spectral power in the sleep spindle range [72]. In agreement with these results, sleep deprivation in mice has been shown to impair calcium-dependent forms of long-term potentiation [88].

With regard to neuroanatomical dynamics, experience-dependent changes in neural physiology have been shown to persist in the neocortex but fade in the hippocampus as firing rate changes during NREM sleep [72], and as increased levels of plasticity-promoting factor during REM sleep (Fig. 1C) [69,72]. These findings implicate sleep in the evolution of hippocampus-dependent memories within the cortex.

Altogether, the available data point to the concerted association, during NREM and REM sleep, of electrophysiological and molecular mechanisms responsible for the sequential processing, i.e., reorganization and synaptic consolidation of memory traces during the NREM-REM sleep cycle $[11,25,70]$. It has been proposed that, following the formation of memories, sleep plays a crucial role in their evolution, first identifying and strengthening relevant memories while erasing memories that are not, and then integrating these new memories with older memories, extracting gist, and discovering rules within newly learned material (11). These functions may likewise require the combined actions of NREM and REM sleep $[2,27,70,82]$, removing or reorganizing memories to free resources for learning new materials and thereby preparing the brain for the upcoming wake period.

\section{From laboratory to classroom}

Given that sleep-dependent learning has been extensively characterized over a wide range of scales and neurobiological mechanisms, what sort of practical recommendations to education can one derive from the science of sleep and memory? A seemingly minor modification has to do with the time of class onset. Adolescents, whose circadian rhythms are better adapted to afternoons [1,49], are handicapped for morning learning $[29,101]$, in part due to sleep inertia $[24,84]$ and to the substantial modifications in sleep patterns and hormonal regulation experienced by teenagers [28]. Phase delays in the circadian timing of sleep during adolescence can favor the accumulation of persisting sleep deficits if school starts too early. Thus, the time required for commuting to school is inversely correlated with sleep duration [58], and both increased television viewing and obesity are associated with reduced sleep duration [56,96].

In the laboratory setting, sleep deficits are very detrimental to learning. While most studies to date have focused on the benefits of post-learning sleep for memory consolidation, some recent studies point to the key role of pre-learning sleep for the encoding of new memories $[2,86,92,104]$. The sleep-dependent mechanisms underlying this important preparatory role of sleep likely include the replenishment of calcium stores, macromolecules, and vesicles, as well as the removal of neurotoxic metabolites $[8,43,102]$, along with more general improvements in attention [87].

How to deal with the problem of sleep deficits in schools? As earlier bedtimes do not alleviate the circadian phase delay of sleep in adolescence, a delay in the start time of classes has been proposed as a potentially efficacious way to improve education at a remarkably lost cost $[55,91]$. As straightforward as this seems, changes in school start times are not well received by parents who are constrained by workplace schedules. A more controversial option is the introduction of naps into the school schedule. Many forms of sleep-dependent learning, including that of simple facts, occur optimally within a few hours after initial memory acquisition [11,22]. Such sleep can stabilize recently learned material, making it resistant to the normal loss that occurs over the day $[16,17]$. The standard lag of several hours between morning classroom learning and sleep onset in the evening likely causes classroom contents to suffer interference from afternoon waking activities. Rather than changing school schedules to allow more sleep at home, or preventing students from sleeping at school, sleep might be embraced as a pedagogical tool. Post-training naps have been shown to rescue perceptual fatigue [47], and to promote gains in procedural task performance $[46,95]$ and hippocampaldependent visuo-spatial learning $[51,73]$ similar to gains observed following a full night of sleep. In children, sleep-dependent benefits have been shown primarily for declarative memories [61,97]. This is providential for the goal of employing naps as a pro-mnemonic practice in the schools, as diurnal naps mainly involve NREM sleep [47], and most school content is comprised of declarative memories.

Studies in infants 18-months of age have shown that naps promote abstraction of grammar in language learning experiments [26], gains which are retained over a subsequent night of sleep [32]. Among preschoolers in childcare, one study found daytime naps to be negatively correlated with neuropsychological measurements of vocabulary and auditory attention span, while nighttime sleep was positively correlated with vocabulary [39]. One interpretation of these results is that children who receive inadequate sleep at night sleep are more likely to take daytime naps. But it may also be that these naps, within the daycare environment, lack the physiological features required to support memory consolidation. Notwithstanding, an electroencephalographic assessment of daytime naps among preschoolers found that such naps significantly benefit visuo-spatial learning, compared to equivalent waking intervals. Nap-dependent learning was the greatest for children habituated to daily naps, and was not rescued by subsequent overnight sleep [37]. Importantly, sleep spindle density was strongly correlated with this napdependent learning among preschoolers (Fig. 1D). Finally, a study of sixth grade students found that post-training naps of $\sim 2 \mathrm{~h}$ improved memory retention measured 5 days later [41].

One caveat to consider here is that afternoon naps reduce the propensity for sleep in the evening. Nocturnal sleep in children who 
habitually nap is less deep and contains less slow wave activity, and thus might be less effective in supporting various forms of memory consolidation [99]. A second concern is that short ( $<60$ min) naps contain little or no REM sleep, and my not benefit complex learning with declarative, procedural and emotional features. In such cases, it may be optimal to learn in the morning, when vigilance is high, and to briefly rehearse the learned material in the late afternoon or early evening to optimize its consolidation during fully developed nocturnal NREM-REM cycles.

Another approach to optimizing sleep-dependent benefits for classroom learning is to take advantage of the fact that sleep appears to be especially beneficial for memories deemed relevant by the subject; the expectation of future utility strongly biases the effect of sleep on memory persistence $[10,12,98]$. Thus, efforts to make clear to students the value of what is being learned whether because it will be on a future test or because it will be valuable in their ongoing life - gain an extra benefit in terms of enhancing subsequent sleep-dependent consolidation of what was learned. Explicit pre-sleep rehearsal of newly acquired declarative contents may selectively enhance this school learning by identifying it as having future relevance.

Yet another controversial low-cost implementation is to make naps available upon request. Students could be instructed to request a nap whenever feeling too drowsy to learn more. This would allow them to prepare for memory acquisition following a bad night of sleep, and to self-regulate the offline consolidation of relevant memories soon after learning, as has been suggested for preschool children [36]. However, allowing students to nap upon request bears several risks. First students might forego adequate nocturnal sleep, knowing that they can make it up at school. Even in the best of circumstances, such napping might lead to sleep that is no longer synchronized with one's circadian rhythms, and which might lose its efficacy as a cognitive enhancer. Finally, such a change would require more flexibility in the way classroom contents are presented. On the other hand, the amount of brief napping seen in classrooms even now, especially at the high school level, is considerable, and studies suggest that as little as 6 min of sleep can enhance recently encoded declarative memories $[5,38]$. Perhaps students have already intuitively identified a simple way of enhancing memory.

Over the longer term, the issue arises of whether educational institutions should adopt research approaches aimed at specifically improving the cognitive functions of sleep. While pharmacological interventions to improve sleep-dependent memory consolidation have so far largely failed (e.g. [18]), relatively simple brain stimulation techniques have successfully enhanced declarative memory consolidation during sleep in healthy students. Transcranial direct current stimulation oscillating in the frequency of the sleep slow oscillation applied during nocturnal sleep significantly enhanced students' memory for vocabulary words they had learned prior to the stimulated sleep [45]. A distinct enhancement of sleep-dependent declarative memory consolidation was likewise achieved by auditory closed-loop stimulation, where short low-intensity clicks were presented "in-phase" with the up-state of EEG slow oscillations detected during slow wave sleep [50]. Electrical stimulation of slow oscillations during a nap also improved post-sleep learning [2]. While the stimulation of specific EEG oscillations has potential for school learning, substantially more research on the possible unwanted side effects of such stimulation, as well as considerations of ethical issues, is needed before any application in educational settings can be seriously considered.

Whereas methods aimed to enhance the EEG oscillatory characteristics of slow wave sleep are known to promote secondary improvements in consolidation and post-sleep encoding of new memories, a more direct approach to strengthen memories is to reactivate them during sleep. A promising technique of enhancing specific memories is to associate the learning of specific information with either unique odors or sounds, and then replaying the sound, or presenting the odors, during subsequent sleep (Fig. 1E). Such memory reactivation during sleep has led to enhanced declarative memory [64,73,77], as well as improved stimulus-specific extinction of fear conditioning [30]. Other studies in humans and rats have shown that reactivation is similarly effective when auditory cues are presented during slow wave sleep and that cuing can also be used to select specific memories to be strengthened during sleep $[4,73]$. The targeted cuing and reactivation of specific memory traces during slow wave sleep may provide scalable, low-cost improvement of classroom learning.

\section{Are dreams important for cognition?}

Another aspect of sleep that may be of educational value is dreaming. Widely valued during most of our historical past as a source of insights [75], dreaming is no longer considered of importance in contemporary society. In the past decades it became common to consider dreams as devoid of cognitive value, mere "spandrels of sleep" that only reflect sleep-related physiological variables [19]. Yet, recent research suggests that dreams may constitute an untapped source of cognitive enhancement in schools. Experiments using maze navigation as a spatial cognitive task showed that task-related dream content is associated with performance gains over time, while task-related waking thoughts are not [94]. Whether this relationship is causal or correlative remains to be determined. Dreams may represent behavioral simulations able to integrate complex knowledge from the past into future action plans [7,66,71]. REM sleep, the state when the most vivid dreaming takes place, is also involved in the processing of emotional memories $[40,52,85,89]$. It is possible that complex learning with spatial and/or emotional aspects is particularly prone to benefit from dreaming, perhaps even from the conscious examination of dream contents [20], but at present this remains speculative. The cognitive function of dreaming remains enigmatic and constitutes a research frontier in need of critical experimentation and analysis.

\section{Conclusions}

There is a large body of evidence regarding the cognitive role of sleep, but relatively few successful applications of this knowledge to the school setting. Translational research on how to optimize sleep so as to maximally benefit school learning is timely and much needed, offering an opportunity for discovering scalable, low-cost, and socially relevant pedagogical methodologies. Some concrete ideas to be subjected to quantitative empirical testing include (1) the availability of school naps both before and after classes, (2) mnemonic cueing during sleep, and (3) the use of presleep instructions to enhance the expectation of future utility for specific memories learned. However, in parallel with such testing, more basic studies are still needed (1) to confirm or clarify the extent to which the forms of sleep-dependent consolidation seen in collegeaged students and adults are active in children as young as preschool ages, and (2) to demonstrate that the types of information taught in schools and the forms in which this information is delivered in the classroom are amenable to sleep-dependent consolidation, especially when measured with the types of tests used in the classroom. While we believe that there is already sufficient data to justify moving towards implementation of these suggestions, the studies outlined here would facilitate both the optimization of this approach and its justification to policy makers capable of implementing such change. 


\section{Acknowledgments}

We thank the James S. McDonnell Foundation for support of the Latin American School for Education, Cognitive and Neural Sciences, and Dr. Jan Born for intellectual input and critical reading of the manuscript.

\section{References}

[1] Andrade MM, Benedito-Silva AA, Domenice S, Arnhold IJ, Menna-Barreto L. Sleep characteristics of adolescents: a longitudinal study. J Adolesc Health 1993;14(5):401-6.

[2] Antonenko D, Diekelmann S, Olsen C, Born J, Molle M. Napping to renew learning capacity: enhanced encoding after stimulation of sleep slow oscillations. Eur J Neurosci 2013;37(7):1142-51.

[3] Benchenane K, Peyrache A, Khamassi M, Tierney PL, Gioanni Y, Battaglia FP, et al. Coherent theta oscillations and reorganization of spike timing in the hippocampal-prefrontal network upon learning. Neuron 2010;66(6):921-36.

[4] Bendor D, Wilson MA. Biasing the content of hippocampal replay during sleep. Nat Neurosci 2012;15:1439-44.

[5] Brooks A, Lack L. A brief afternoon nap following nocturnal sleep restriction which nap duration is most recuperative? Sleep 2006:29(6):831-40.

[6] Chauvette S, Seigneur J, Timofeev I. Sleep oscillations in the thalamocortica system induce long-term neuronal plasticity. Neuron 2012;75(6):1105-13.

[7] Cheyne JA. Play, dreams and simulation. Behav Brain Sci 2000;23(6):918-9.

[8] Cirelli C, Gutierrez CM, Tononi G. Extensive and divergent effects of sleep and wakefulness on brain gene expression. Neuron 2004;41(1):35-43.

[9] Clemens Z, Molle M, Eross L, Barsi P, Halasz P, Born J. Temporal coupling of parahippocampal ripples, sleep spindles and slow oscillations in humans. Brain 2007:130(Pt 11):2868-78.

[10] Cohen DA, Pascual-Leone A, Press DZ, Robertson EM. Off-line learning of motor skill memory: a double dissociation of goal and movement. Proc Nat Acad Sci USA 2005;102(50):18237-41.

[11] Diekelmann S, Born J. The memory function of sleep. Nat Rev Neurosc 2010;11(2):114-26

[12] Diekelmann S, Wilhelm I, Wagner U, Born J. Sleep to implement an intention. Sleep 2013;36(1):149-53.

[13] Djonlagic I, Rosenfeld A, Shohamy D, Myers C, Gluck M, Stickgold R. Sleep enhances category learning. Learn Mem 2009;16(12):751-5.

[14] Dragoi G, Tonegawa S. Preplay of future place cell sequences by hippocampal cellular assemblies. Nature 2011;469(7330):397-401.

[15] Ellenbogen JM, Hu PT, Payne JD, Titone D, Walker MP. Human relational memory requires time and sleep. Proc Natl Acad Sci USA 2007;104 (18):7723-8.

[16] Ellenbogen JM, Hulbert JC, Jiang Y, Stickgold R. The sleeping brain's influence on verbal memory: boosting resistance to interference. PLoS One 2009;4(1): e4117.

[17] Ellenbogen JM, Hulbert JC, Stickgold R, Dinges DF, Thompson-Schill SL. Interfering with theories of sleep and memory: sleep, declarative memory, and associative interference. Curr Biol 2006;16:1290-4.

[18] Feld GB, Wilhelm I, Ma Y, Groch S, Binkofski F, Molle M, et al. Slow wave sleep induced by GABA agonist tiagabine fails to benefit memory consolidation. Sleep 2013;36(9):1317-26.

[19] Flanagan O. Dreaming is not an adaptation. Behav Brain Sci 2000;23 (6):936-9.

[20] Freud S. The Interpretation of Dreams. 1952 ed.. London: Encyclopaedia Britannica; 1900.

[21] Gais S, Albouy G, Boly M, Dang-Vu TT, Darsaud A, Desseilles M, et al. Sleep transforms the cerebral trace of declarative memories. Proc Natl Acad Sci USA 2007;104(47):18778-83.

[22] Gais S, Lucas B, Born J. Sleep after learning aids memory recall. Learn Mem 2006;13(32):259-62.

[23] Gais S, Molle M, Helms K, Born J. Learning-dependent increases in sleep spindle density. J Neurosci 2002;22(15):6830-4.

[24] Giannasi LC, Magini M, Costa MS, Oliveira CS, Oliveira LV. Oral appliance treatment for obstructive sleep apnea in a partly edentulous patient. Am J Orthod Dentofac Orthop 2010;137(4):548-51.

[25] Giuditta A, editor. Stuttgart: Fisher-Verlag; 1985.

[26] Gomez RL, Bootzin RR, Nadel L. Naps promote abstraction in languagelearning infants. Psychol Sci 2006;17(8):670-4.

[27] Grosmark AD, Mizuseki K, Pastalkova E, Diba K, Buzsaki G. REM sleep reorganizes hippocampal excitability. Neuron 2012;75(6):1001-7.

[28] Hagenauer MH, Lee TM. Adolescent sleep patterns in humans and laboratory animals. Horm Behav 2013;64(2):270-9.

[29] Hansen M, Janssen I, Schiff A, Zee PC, Dubocovich ML. The impact of schoo daily schedule on adolescent sleep. Pediatrics 2005;115(6):1555-61.

[30] Hauner KK, Howard JD, Zelano C, Gottfried JA. Stimulus-specific enhancement of fear extinction during slow-wave sleep. Nat Neurosci 2013;16 (11):1553-5

[31] Huber R, Ghilardi MF, Massimini M, Tononi G. Local sleep and learning. Nature 2004;430(6995):78-81.

[32] Hupbach A, Gomez RL, Bootzin RR, Nadel L. Nap-dependent learning in infants. Dev Sci 2009;12(6):1007-12.
[33] Inostroza M, Born J. Sleep for preserving and transforming episodic memory. Annu Rev Neurosci 2013;36:79-102.

[34] Jadhav SP, Kemere C, German PW, Frank LM. Awake hippocampal sharpwave ripples support spatial memory. Science 2012;336(6087):1454-8.

[35] Jenkins JB, Dallenbach KM. Oblivescence during sleep and waking. Am J Psychol 1924;35:605-12.

[36] Jones CH, Ball HL. Napping in English preschool children and the association with parents' attitudes. SleepMed 2013;14(4):352-8.

[37] Kurdziel L, Duclos K, Spencer RM. Sleep spindles in midday naps enhance learning in preschool children. Proc Natl Acad Sci USA 2013;110 (43):17267-72.

[38] Lahl O, Wispel C, Willigens B, Pietrowsky R. An ultra short episode of sleep is sufficient to promote declarative memory performance. J Sleep Res 2008; $17: 3-10$.

[39] Lam JC, Mahone EM, Mason T, Scharf SM. The effects of napping on cognitive function in preschoolers. J Dev Behav Pediatr 2011;32(2):90-7.

[40] Lara-Carrasco J, Nielsen TA, Solomonova E, Levrier K, Popova A. Overnight emotional adaptation to negative stimuli is altered by REM sleep deprivation and is correlated with intervening dream emotions. J Sleep Res 2009;18 (2):178-87.

[41] Lemos N, Weissheimer J, Dias A, Ribeiro S. Investigation of the role of sleep in school learning. In: Proceedings of the XXVI annual meeting of the Federation of Experimental Biology Societies (FeSBE). Rio de Janeiro; 2011.

[42] Louie K, Wilson MA. Temporally structured replay of awake hippocampal ensemble activity during rapid eye movement sleep. Neuron 2001;29 (1):145-56.

[43] Mackiewicz M, Shockley KR, Romer MA, Galante RJ, Zimmerman JE, Naidoo $\mathrm{N}$, et al. Macromolecule biosynthesis: a key function of sleep. Physiol Genomics 2007;31:441-57.

[44] Maquet P, Laureys S, Peigneux P, Fuchs S, Petiau C, Phillips C, et al. Experience-dependent changes in cerebral activation during human REM sleep. Nat Neurosci 2000:3(8):831-6.

[45] Marshall L, Helgadottir H, Molle M, Born J. Boosting slow oscillations during sleep potentiates memory. Nature 2006;444(7119):610-3.

[46] Mednick S, Nakayama K. Stickgold R. Sleep-dependent learning: a nap is as good as a night. Nat Neurosci 2003;6(7):697-8.

[47] Mednick SC, Nakayama K, Cantero JL, Atienza M, Levin AA, Pathak N, et al. The restorative effect of naps on perceptual deterioration. Nat Neurosci 2002;5(7):677-81.

[48] Molle M, Eschenko O, Gais S, Sara SJ, Born J. The influence of learning on sleep slow oscillations and associated spindles and ripples in humans and rats. Eur J Neurosci 2009;29(5):1071-81.

[49] Natal CL, Lourenco TJ, Silva LA, Boscolo RA, Silva A, Tufik S, et al. Gender differences in the sleep habits of 11-13 year olds. Rev Bras Psiquiatr 2009;31 (4):358-61.

[50] Ngo HV, Martinetz T, Born J, Molle M. Auditory closed-loop stimulation of the sleep slow oscillation enhances memory. Neuron 2013;78(3):545-53.

[51] Nguyen ND, Tucker MA, Stickgold R, Wamsley EJ. Overnight sleep enhances hippocampus-dependent aspects of spatial memory. Sleep 2013;36 (7):1051-7.

[52] Nishida M, Pearsall J, Buckner RL, Walker MP. REM sleep, prefrontal theta, and the consolidation of human emotional memory. Cereb Cortex 2009;19 (5):1158-66.

[53] Nishida M, Walker MP. Daytime naps, motor memory consolidation and regionally specific sleep spindles. PLoS One 2007:2(4):e341.

[54] Orban P, Rauchs G, Balteau E, Degueldre C, Luxen A, Maquet P, et al. Sleep after spatial learning promotes covert reorganization of brain activity. Proc Natl Acad Sci USA 2006;103(18):7124-9.

[55] Owens JA, Belon K, Moss P. Impact of delaying school start time on adolescent sleep, mood, and behavior. Arch Pediatr Adolesc Med 2010;164:608-14.

[56] Padez C, Mourao I, Moreira P, Rosado V. Long sleep duration and childhood overweight/obesity and body fat. Am J Hum Biol 2009;21(3):371-6.

[57] Pavlides C, Winson J. Influences of hippocampal place cell firing in the awake state on the activity of these cells during subsequent sleep episodes. J Neurosci 1989;9(8):2907-18.

[58] Pereira EF, Moreno C, Louzada FM. Increased commuting to school time reduces sleep duration in adolescents. Chronobiol Int 2013.

[59] Peyrache A, Khamassi M, Benchenane K, Wiener SI, Battaglia FP. Replay of rule-learning related neural patterns in the prefrontal cortex during sleep. Nat Neurosci 2009;12(7):919-26.

[60] Plihal W, Born J. Effects of early and late nocturnal sleep on declarative and procedural memory. J Cogn Neurosci 1997;9:534-47.

[61] Prehn-Kristensen A, Göder R, Chirobeja S, Bressmann I, Ferstl R, Baving L. Sleep in children enhances preferentially emotional declarative but not procedural memories. J Exp Child Psychol 2009;104(1):132-9.

62] Ramey CT, Campbell FA, Burchinal M, Skinner ML, Gardner DM, Ramey SL. Persistent effects of early childhood education on high-risk children and their mothers. Appl Dev Sci 2000;4(1):2-14.

[63] Rasch B, Born J. About sleep's role in memory. Physiol Rev 2013;93 (2):681-766.

[64] Rasch B, Buchel C, Gais S, Born J. Odor cues during slow-wave sleep prompt declarative memory consolidation. Science 2007;315(5817):1426-9.

[65] Reardon SF. The widening income achievement gap. Educ Leadersh 2013;70 (8):10-6. 
[66] Revonsuo A. The reinterpretation of dreams: an evolutionary hypothesis of the function of dreaming. Behav Brain Sci 2000;23(6):877-901.

[67] Ribeiro S, Gervasoni D, Soares ES, Zhou Y, Lin SC, Pantoja J, et al. Long-lasting novelty-induced neuronal reverberation during slow-wave sleep in multiple forebrain areas. PLoS Biol 2004;2(1):E24.

[68] Ribeiro S, Goyal V, Mello CV, Pavlides C. Brain gene expression during REM sleep depends on prior waking experience. Learn Mem 1999;6(5):500-8.

[69] Ribeiro S, Mello CV, Velho T, Gardner TJ, Jarvis ED, Pavlides C. Induction of hippocampal long-term potentiation during waking leads to increased extrahippocampal zif-268 expression during ensuing rapid-eye- movement sleep. J Neurosci 2002;22(24):10914-23.

[70] Ribeiro S, Nicolelis MAL. Reverberation, storage and postsynaptic propagation of memories during sleep. Learn Mem 2004;11(6):686-96.

[71] Ribeiro S, Nicolelis MAL. The evolution of neural systems for sleep and dreaming. In: Kaas J, editor. Evolution of nervous systems, vol. 3. New York: Elsevier; 2006. p. 451-64.

[72] Ribeiro S, Shi X, Engelhard M, Zhou Y, Zhang H, Gervasoni D, et al. Novel experience induces persistent sleep-dependent plasticity in the cortex but not in the hippocampus. Front Neurosci 2007;1(1):43-55.

[73] Rudoy JD, Voss JL, Westerberg CE, Paller KA. Strengthening individual memories by reactivating them during sleep. Science 2009;326(5956):1079.

[74] Schabus M, Hoedlmoser K, Pecherstorfer T, Anderer P, Gruber G, Parapatics S, et al. Interindividual sleep spindle differences and their relation to learningrelated enhancements. Brain Res 2008:1191:127-35.

[75] Shulman D, Stroumsa GG, Stroumsa GAG. Dream cultures: explorations in the comparative history of dreaming. Oxford: Oxford University Press; 1999.

[76] Smith C, Smith D. Ingestion of ethanol just prior to sleep onset impairs memory for procedural but not declarative tasks. Sleep 2003;26(2):185-91.

[77] Smith C, Weeden K. Post training REMs coincident auditory stimulation enhances memory in humans. Psychiatr J Univ Ott 1990;15(2):85-90.

[78] Stickgold R. How do I remember? Let me count the ways Sleep Med Rev 2009;13:305-8.

[79] Stickgold R, James L, Hobson JA. Visual discrimination learning requires sleep after training. Nat Neurosci 2000;3(12):1237-8.

[80] Stickgold R, Walker MP. Sleep-dependent memory triage: evolving generalization through selective processing. Nat Neurosci 2013;16(2):139-45.

[81] Tamaki M, Matsuoka T, Nittono H, Hori T. Fast sleep spindle (13-15 Hz) activity correlates with sleep-dependent improvement in visuomotor performance. Sleep 2008;31(2):204-11.

[82] Tononi G, Cirelli C. Sleep function and synaptic homeostasis. Sleep Med Rev 2006:10(1):49-62.

[83] Ulloor J, Datta S. Spatio-temporal activation of cyclic AMP response elementbinding protein, activity-regulated cytoskeletal-associated protein and brain-derived nerve growth factor: a mechanism for pontine-wave generator activation-dependent two-way active-avoidance memory processing in the rat. J Neurochem 2005;95(2):418-28.

[84] Van De Werken M, Gimenez MC, De Vries B, Beersma DG, Van Someren EJ, Gordijn MC. Effects of artificial dawn on sleep inertia, skin temperature, and the awakening cortisol response. J Sleep Res 2010;19(3):425-35.

[85] van der Helm E, Yao J, Dutt S, Rao V, Saletin JM, Walker MP. REM sleep depotentiates amygdala activity to previous emotional experiences. Curr Biol 2011;21(23):2029-32.

[86] Van Der Werf YD, Altena E, Schoonheim MM, Sanz-Arigita EJ, Vis JC, De Rijke W, et al. Sleep benefits subsequent hippocampal functioning. Nat Neurosci 2009;12(2):122-3.
[87] Van Dongen HP, Maislin G, Mullington JM, Dinges DF. The cumulative cost of additional wakefulness: dose-response effects on neurobehavioral functions and sleep physiology from chronic sleep restriction and total sleep deprivation. Sleep 2003;26:117-26.

[88] Vecsey CG, Baillie GS, Jaganath D, Havekes R, Daniels A, Wimmer M, et al. Sleep deprivation impairs cAMP signalling in the hippocampus. Nature 2009;461(7267):1122-5.

[89] Wagner U, Gais S, Born J. Emotional memory formation is enhanced across sleep intervals with high amounts of rapid eye movement sleep. Learn Mem 2001;8(2):112-9.

[90] Wagner U, Gais S, Haider H, Verleger R, Born J. Sleep inspires insight. Nature 2004; $427: 352-5$

[91] Wahistrom K. Changing times: findings from the first longitudinal study of later high school start times. NASSP Bull 2002;86:3-21.

[92] Walker MP. Sleep-dependent memory processing. Harv Rev Psychiatry 2008;16(5):287-98.

[93] Walker MP, Liston C, Hobson JA, Stickgold R. Cognitive flexibility across the sleep-wake cycle: REM-sleep enhancement of anagram problem solving. Brain Res Cogn Brain Res 2002;14(3):317-24.

[94] Wamsley EJ, Tucker M, Payne JD, Benavides JA, Stickgold R. Dreaming of a learning task is associated with enhanced sleep-dependent memory consolidation. Curr Biol 2010;20(9):850-5.

[95] Wamsley EJ, Tucker MA, Payne JD, Stickgold R. A brief nap is beneficial for human route-learning: the role of navigation experience and EEG spectral power. Learn Mem 2010;17(7):332-6.

[96] Wells JC, Hallal PC, Reichert FF, Menezes AM, Araujo CL, Victora CG. Sleep patterns and television viewing in relation to obesity and blood pressure: evidence from an adolescent Brazilian birth cohort. Int J Obes (Lond) 2008;32(7):1042-9.

[97] Wilhelm I, Diekelmann S, Born J. Sleep in children improves memory performance on declarative but not procedural tasks. Learn Mem 2008;15 (5):373-7.

[98] Wilhelm I, Diekelmann S, Molzow I, Ayoub A, Molle M, Born J. Sleep selectively enhances memory expected to be of future relevance. J Neurosci 2011;31(5):1563-9.

[99] Wilhelm I, Rose M, Imhof KI, Rasch B, Buchel C, Born J. The sleeping child outplays the adult's capacity to convert implicit into explicit knowledge. Nat Neurosci 2013;16(4):391-3.

[100] Wilson MA, McNaughton BL. Reactivation of hippocampal ensemble memories during sleep. Science 1994;265(5172):676-9.

[101] Wolfson AR, Carskadon MA. Understanding adolescents' sleep patterns and school performance: a critical appraisal. Sleep Med Rev 2003;7(6):491-506.

[102] Xie L, Kang H, Xu Q, Chen MJ, Liao Y, Thiyagarajan M, et al. Sleep drives metabolite clearance from the adult brain. Science 2014;342(6156):373-7.

[103] Yaroush R, Sullivan MJ, Ekstrand BR. Effect of sleep on memory. II. Differential effect of the first and second half of the night. J Exp Psychol 1971;88 (3):361-6.

[104] Yoo SS, Hu PT, Gujar N, Jolesz FA, Walker MP. A deficit in the ability to form new human memories without sleep. Nat Neurosci 2007;10(3):385-92.

[105] Yordanova J, Kolev V, Wagner U, Born J, Verleger R. Increased alpha (8-12 Hz) activity during slow wave sleep as a marker for the transition from implicit knowledge to explicit insight. J Cogn Neurosci 2012;24(1):119-32. 